\title{
RECREIO DO TRABALHADOR DE SIDEROPOLIS: UM PATRIMÔNIO EM RUÍNAS
}

\author{
Elaine Rodrigues ${ }^{1}$ \\ Michele Gonçalves Cardoso²
}

\begin{abstract}
"Quem te conheceu, nunca vai te esquecer... Foste construído para nossolazer, Carnavais, teatros, bailes desfiles, jogos de bilhar, baralho, dominó e não esquecendo do cinema até presentes de natal recebemos em teu interior. Acolhestes nosso o conjunto américanight. Só não conta a tua Historia quem não viveu contigo, Fiquei 25 anos prolongando tua vida, deixei minha casa minha família, pra cuidar de $t i$ Ficar ao te redor, não fugindo de ventos, trovoadas, chuvas... Recebi Baixo assinado em cima de Baixo assinado pra te largar, É o que queriam, mas fui firme até onde pude. Mas politicamente, recebi uma intimação me proibindo de entrar no teu interior. Não pude manter teu alicerce firme, onde vieste te arrastando sendo depenado, te agonizando, até te deixaram sem tua mobília, onde foi? Ninguém sabe, ninguém viu... De 2005 a 2013, não aguentaste e vieste a baixo, por falta de competência de alguém. Agora só nos restam saudades, recordando tua imagem através de fotos que restam. Que pena só existiu dois igual ati, que até hoje sobrevivem, e tu coitado, te esqueceram Muitos não deram valor, não sabiam da tua História.. Aqueles que foram contra a Associação amigos de Siderópolis, meus parabéns! Vejam o resultado, mas espero que o que restou, como o nosso estádio de futebol, Itaúna Atlético Clube, alguém olhe para nosso consolo." Canela
\end{abstract}

Essa pesquisa foi fomentada pelo projeto PIC. Art.170, vinculada a Universidade do Extremo Sul Catarinense e teve com objetivo registrar memórias sobre o "Recreio do Trabalhador", edificação sede do ITAÚNA Atlético Clube, localizado na antiga vila operária Rio Fiorita em Siderópolis/SC. Um lugar de sociabilidade e de grande valor para comunidade. A edificação foi construída como associação para os funcionários e familiares da Companhia Siderúrgica Nacional CSN. Com o intuito de buscar recursos para o restauro da edificação, no ano de 2007 o mesmo foi tombado como patrimônio histórico. No entanto, o abandono por parte do poder público ocasionou na destruição parcial do prédio alguns anos depois.

\footnotetext{
${ }^{1}$ Acadêmica da $7^{\underline{a}}$ fase do curso de História pela Universidade do Extremo Sul Catarinense - UNESC. Email: nanirodri6@hotmail.com

2 Mestre em história. Doutoranda em História. Bolsista UNIEDU/ FUMDES de Pós-Graduação. Professora do Departamento de História da Universidade do Extremo Sul Catarinense - UNESC. Email; michelegc@unesc.net

${ }^{3}$ Poema escrito por João Agostinho, conhecido como Canela.
} 
Para melhor compreendermos o contexto de construção do "Recreio do Trabalhador" e os diversos embates em torno dessa edificação se faz necessária uma pequena contextualização da atividade carbonífera na região. O sul de Santa Catarina teve seu desenvolvimento econômico, urbano, social e cultural marcado pela exploração carbonífera, atividade que teve seu início em fins do século XIX e início do XX. A descoberta do "ouro negro" incentivou a vinda de muitos/as trabalhadores/as de diferentes regiões catarinenses, como também de outros estados.

A chegada desses/as trabalhadores/as e a riqueza proporcionada pela mineração modificou os contornos das pequenas vilas, cuja economia era baseada na agricultura. As empresas mineradoras ao se instalarem nos municípios do sul catarinense construíram uma série de estruturas que deveriam garantir o "bom" funcionamento dos trabalhos. Essas empresas foram responsáveis pela abertura de diversas minas para a extração do carvão, como também, pelos investimentos nas estruturas de transporte do minério ampliando ramais ferroviários, através da Ferrovia Thereza Cristina, e com investimentos para a construção e ampliação dos Portos de Laguna e Imbituba. Também foram responsáveis pela construção das vilas operárias e de seus espaços de lazer - como os campos de futebol e as sedes recreativas - construindo ainda, armazéns, ambulatórios e as sedes administrativas das próprias empresas. Cada uma dessas construções cumpria um papel fundamental para o funcionamento das atividades carboníferas: seja para extração ou escoamento, seja para controle e disciplinarização dos/as trabalhadores/as das minas.

Essas vilas eram construídas exclusivamente para suprir as necessidades das famílias dos mineiros a exemplo dos modelos europeus (BERNARDO, 2004. $p$ 129). Assim começaram as construções das vilas operárias na região do sul do estado. No início da mineração as casas eram construídas de barro e aos poucos foram substituídas por casas geminadas de madeira, formando assim as vilas operárias como conhecemos ainda hoje. Esse modelo adotado era "o modelo capitalista vivenciado na Europa. Que mostra como tudo na vila operária pertencia à Companhia Mineradora: casas, farmácia, açougue, armazém." (COSTA, 2002. p 105).

No caso da cidade de Siderópolis, as transformações econômicas e urbanas desenvolvidas durante o ciclo do carvão se deram a partir da chegada da 
Companhia Siderúrgica Nacional/ CSN durante a década de 1940. A chegada da estatal marcou uma nova fase do ciclo do carvão. A empresa oferecia melhores salários e suas vilas operárias eram melhores equipadas. As estruturas da empresa também eram diferenciadas. Logo a CSN se tornou um parâmetro para os demais trabalhadores e para as reivindicações do sindicato. Já para o meio ambiente a chegada da estatal foi devastadora.

A construção da vila operária da CSN ocorreu no bairro Rio Fiorita transformando totalmente o cotidiano da cidade.

Com a chegada da CSN - Companhia Siderúrgica Nacional e começo da exploração do carvão, por volta de 1941, surgiu a primeira mina de carvão (galeria) e a montagem da primeira escavadeira. Junto iniciou-se a construção, em massa, de casas operárias em Rio Fiorita. (SCAINI; MAGAGNIN; DUARTE, 2002. p. 71).

A vila operária do bairro era projetada de maneira que os/as operários/as não precisassem sair dela para atender suas necessidades. Ao longo dos anos, a cidade foi crescendo, tudo girava em torno da CSN. Um exemplo da importância da instalação da empresa no município foi a mudança do nome da cidade, antes da chegada da estatal o ainda distrito de Urussanga se chamava Nova Beluno,

Foi em homenagem a Siderúrgica, que o distrito passou a denominar-se
Siderópolis. A Lei municipal $n^{\circ} 60$ de $01 / 07 / 1913$ criou o distrito com a
denominação de Nova Belluno, subordinado ao município de Urussanga.
Em 19/12/1958, através da lei estadual $n^{\circ}=380$, foi desmembrado de
Urussanga, elevando-se à categoria de município com a denominação de
Siderópolis. (FONTE: IBGE)

No ano de 1991, já com o carvão em baixa no mercado, a empresa deixou a cidade o que gerou uma crise afetando a economia e a vida de quem dependia dela para o seu sustento. Com o seu fechamento essas estruturas foram entregues à prefeitura municipal em regime de comodato, conforme consta na Lei № 850/91 onde fica estipulado que:

O chefe do Poder Executivo municipal, autorizado a firmar Contrato de Comodato, a título gratuito, com a Companhia Siderúrgica Nacional - CSN, para a utilização do Recreio do Trabalhador, Jardim de Infância, Campo de Futebol, Ambulatório, Clube União Mineira, Escritório e Portaria, todos 
localizados no Bairro Rio Fiorita, neste Município (Lei № 850/91, 02 de agosto de1991).

Esse contrato era válido por30 anos.Ainda na lei outorgada pelo então prefeito José Antônio Périco, consta que esses bens citados acima, deveriam ser destinados a serviços como saúde, atividades esportivas, lazer, atividades escolares e ainda para instalação de indústrias, respeitando as características dos imóveis.

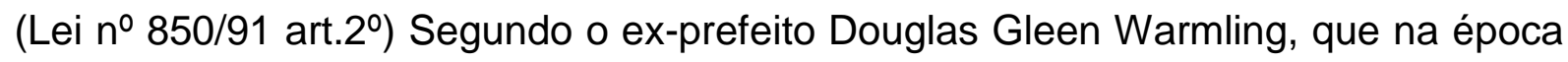
era vereador, no ano de 1997, esses prédios foram definitivamente comprados pelo município, por um valor simbólico de $R \$ 1,00$. ${ }^{4}$ Os pavilhões onde funcionavam as oficinas e almoxarifado acabaram doados a empresas no intuito de gerarem novos empregos,a Portaria do escritório (ou Casa do Guarda) e o ambulatório foram doados à associação de moradores do Bairro Rio Fiorita, alguns prédios citados na lei já não existem mais.

É nesse contexto que buscamos analisar os usos e as disputas em torno do prédio do clube "Recreio dos Trabalhadores". A edificação foi construída no ano de 1954 como sede do então Itauna Atlético Clube, fundado em 04 de dezembro de 1952, por funcionários da CSN. Constituída em sua maioria por trabalhadores, a associação era uma reivindicação dos mesmos, que necessitavam de um lugar de lazer.Diversos eventos sociais aconteciam nesse local, por meio das fotografias podemos observar o envolvimento de grande parte da sociedade em eventos, festas, cinema, etc.

No local também funcionava diariamente um bar, onde os funcionários se reuniam após a jornada de trabalho. Ali bebiam, jogavam dominó, baralho, passavam o seu tempo livre. Além dos funcionários, a própria empresa utilizava o clube para promoção de festas e jantares. O espaço também era utilizado pelo sindicato dos mineiros que realizava suas reuniões e assembleias para deliberações diversas. Abandonado pelo poder público, em abril de 2013 parte sua estrutura desabou.

Seu João Agostinho, morador do bairro há 60 anos, conhecido na cidade como "canela" começou a trabalhar na CSN como laboratorista em 1978. Também fez parte da diretoria do Itaúna, e segundo ele, todo funcionário da CSN automaticamente se tornava sócio do Itaúna. Sócios particulares somente eram ${ }^{4}$ Entrevista realizada com Douglas Gleen Warmling concedida à Elaine Rodrigues no dia 03 de
Fevereiro de 2016 
aceitos caso fossem apresentados por algum outro associado. ${ }^{5}$ Seu "canela" como gosta de ser chamado conta que:

O Recreio pra mim foi tudo, foi minha segunda casa, eu fiquei 25 anos ali, eu fazia e desfazia tudo ali dentro, as próprias fechaduras foi tudo eu que botei, as manutenções tudo eu fazia, isso depois que a CSN foi desativada. [...] Foi todo mundo caindo fora, saindo de Siderópolis, e ficou pra mim porque eu gostava. Eu sempre fiquei ali dentro e não quis que as coisas se acabassem, eu tomei a frente e fiquei cuidando do Recreio, campo de futebol. Até durou muito. ${ }^{6}$

Seu João cuidou do clube de 1991 até 2005. Quando o Prefeito Douglas Gleen Warmling assumiu a prefeitura,solicitou sua saída. Assim,observou o desgaste do prédio ao longo dos anos até a queda parcial de sua estrutura.

Da muita saudade né. Hoje em dia não tem lugar pra ir, os filhos da gente hoje não tem lugar pra sair ai tem que ir fora né. Agora nós fiquemo sem nada, entendeu? [...] não tem mais nada pra nós aqui. A gente leva muita saudade [...] hoje em dia o que eu queria, eu queria o Recreio desse alguma coisa né, que alguém se movimentava e nós erguesse o Recreio. ${ }^{7}$

Ele ainda teve o cuidado de guardar consigo alguns documentos em que estão registradas várias atividades do clube ao longo dos anos. $\mathrm{O}$ acervo conta com livros caixas, relatórios do cinema, jogos, partidas de futebol, programações dos eventos promovidos no local entre outros. Ele conta que guarda tudo com muito carinho, pois cuidava mais do clube do que sua própria casa.

Já em outra entrevista, a moradora do bairro há 63 anos e membro da Associação de Moradores do Bairro Rio Fiorita, Ana Mำ Ferraro Rodrigues, conta que sua relação com o Recreio é muito forte, pois foi onde passou sua juventude. Era lá que aproveitavam os bailes, carnaval e cinema, pois era o único lugar que tinham pra sair. "Tudo foi se perdendo, hoje nossa juventude não tem nada. A gente tinha muito e por causa de negligência das pessoas que não valorizaram o patrimônio deixado pela CSN, hoje encontra-se em ruínas."8

\footnotetext{
${ }^{5}$ Entrevista Realizada com João Agostinho morador do bairro, em 22 de março de 2016 à Elaine Rodrigues.

6 Idem

7 Idem

${ }^{8}$ Entrevista realizada com Ana MํäFerraro Rodrigues concedida à Elaine Rodrigues em 28 de fevereiro de 2016
} 
Percebemos nas entrevistas a importância do clube para a comunidade o que reforça o valor identitário a ele atribuído. As memórias relacionadas a este espaço de sociabilidade ainda estão enraizadas nas lembranças da comunidade se caracterizando não apenas como patrimônio local, mas de toda região carbonífera.

Podemos definir patrimônio como um conjunto de bens materiais e imateriais que se referem à história de uma sociedade, é a herança de nossos antepassados que são transmitidos a gerações futuras. Os patrimônios culturais:

Remanescentes materiais de cultura são testemunhos de experiências vividas, coletiva ou individualmente, e permitem aos homens lembrar e ampliar o sentimento de pertencer a um mesmo espaço, de partilhar uma mesma cultura e desenvolver a percepção de um conjunto de elementos comuns, que fornecem o sentido de grupo e compõe a identidade coletiva. (RODRIGUES, 2009. p.17)

O patrimônio se constitui não apenas de edificações, mas de lugares, objetos, expressões, monumentos que evocam memórias de uma determinada sociedade. Porém, devemos ressaltar que esses patrimônios históricos estão sempre em processo de transformação, por isso se faz importante seu uso e sua preservação. A preservação só faz sentido para a sociedade se está relacionada a necessidades e interesses do momento presente.

As questões que envolvem o patrimônio são fundamentais para a compreensão e salvaguarda das diversas expressões culturais, artísticas e arquitetônicas que fazem parte da nossa sociedade. Necessitam de um conjunto de fatores para que se possa efetivamente por em prática ações de preservação e dar uso a esses locais que evocam lembranças de tempos passados. Para que isso aconteça deve-se primeiramente ter a percepção do que essas edificações e ou costumes representam e qual o papel que elas exercem sobre a sociedade em que estão inseridas.

Os patrimônios assumem importantes significados por fazerem parte da memória coletiva de determinado grupo, a memória de um passado comum e de uma identidade social que faz com que o grupo se sinta parte daquele lugar, do espaço. Nada impede que esse lugar se torne parte integrante do cotidiano, os usos atribuídos a ele, pode permitir uma integração daquele bem sem a necessidade de congelá-lo no passado. Tombar não significa cristalizar no tempo ou inviabilizar 
qualquer obra que contribua para a melhoria da cidade e sim preservar e revitalizar o espaço.

O tombamento foi (e ainda é) frequentemente compreendido como sinônimo de desapropriação ou "congelamento", alimentando disputas que opõe a permanência do "passado" à logica necessariamente destruidora do "progresso". (GONÇALVES, 2012. p.5)

Outro agravante é a falta de cuidados nas edificações tombadas. Tombar um bem material implica em várias responsabilidades por parte do poder público, que muitas vezes não está disposto ou não possui verbas para sua manutenção. Muitos prédios tombados acabam sem ter uma função social e com o passar dos anos se deteriorando e assim tornam-se um problema não apenas para os órgãos públicos como para a própria comunidade na qual esta inserida.

Problemas com relação ao tombamento podem ser observados em Siderópolis.Em 2007, o então prefeito da cidade Douglas Glenn Warmling, decretou o tombamento do "Recreio do Trabalhador" a nível municipal pela Lei nํ 1693, de 20 de julho de 2007. Sua expectativa era que com o tombamento conseguisse viabilizar recursos para seu restauro e manutenção. Porém, todas as suas tentativas foram frustradas o que levou a queda da estrutura no ano de 2013 como dito anteriormente. Hoje, não apenas o clube, mas todas as estruturas deixadas pela Companhia Siderúrgica Nacional aguardam a ação de órgãos competentes para que se restaurem esses bens, e para que a comunidade se aproprie devidamente deles.

Precisamos romper a lógica do descarte e do progresso que se faz presente constantemente no mundo moderno, onde o antigo se contrapõe ao novo. Encontramos vários problemas na manutenção e preservação de nossos bens culturais, seja no âmbito público ou privado, precisamos estar em constante aprofundamento na busca de novas possibilidades que reverberem em práticas de salvaguarda, seja para bens materiais ou imateriais. Para isso é imprescindível à participação ativa da comunidade, pois é a partir dela que serão encontrados meios para manutenção e valorização desses patrimônios, pensando em uma educação patrimonial pautada na cidadania, pois não se pode voltar-se a uma educação efetiva sem que haja uma conscientização e conhecimento do passado, da história. 


\section{REFERÊNCIAS}

AGOSTINHO, João. Entrevista concedida a Elaine Rodrigues. Siderópolis 22 de Mar. de 2016. Entrevista.

BRASIL. Instituto Brasileiro de Geografia e Estatística - IBGE. Histórico Siderópolis. Disponível em:

<http://cidades.ibge.gov.br/painel/historico.php?lang=\&codmun=421760\&search=san ta-catarina|sideropolis|infograficos:-historico>Acesso em: 28 de maio de 2016.

ERNARDO, Roseli Teresinha. O tempo e os espaços de entretenimento das famílias operárias mineiras. In: GOULARTI FILHO, Alcides. Memória e cultura do carvão em Santa Catarina. Florianópolis: Cidade futura, 2004. 129 p.

CAROLA, Carlos Renato. Dos subterrâneos da história: as trabalhadoras das minas de carvão de Santa Catarina (1937-1964) Florianópolis: Ed. da UFSC, 2002.

COSTA, Marli de Oliveria. A infância e as Vilas Operárias Mineiras da CSN. In: CAROLA, Carlos Renato (Org.). Memória e cultura do carvão em Santa Catarina: impactos sociais e ambientais. Santa Cruz do Sul, RS: EDUNISC, 2011.

GONÇALVES, Janice. Da educação do público à participação cidadã: sobre as ações educativas e patrimônio cultural. № 19, 2014. Revista do Museu e Arquivo Histórico La Salle.

Patrimônio em litígio: conflitos e tensões nos tombamentos estaduais catarinenses. Anais do XIV encontro estadual de história - tempo, memórias e expectativas, 2012, UDESC, Florianópolis, SC.

LANDIM, Paula. Percepção e Preservação do Patrimônio Arquitetônico. In: V Seminário Nacional. I Encontro Latino Americano de Preservação e Revitalização Ferroviária. Anais. Piracicaba, SP, 2001. (online)

LEMOS, Carlos A. C. O que é patrimônio histórico. São Paulo: Ed. Brasiliense, 1981.

RODRIGUES, Ana Maria Ferraro. Entrevista concedida a Elaine Rodrigues. Siderópolis 28 de Fev. de 2016. Entrevista.

RODRIGUES, Marly. Preservar e consumir: o patrimônio histórico e o turismo. In: FUNARI, Pedro Paulo; PINSKY, Jaime (Orgs.). Turismo e patrimônio cultural. ed. São Paulo: Contexto, 2003.p. 15-24.

SCAINI, Jucélia Longo; MAGAGNIN, Liana; DUARTE, Márcia RoseleneBarg. Conhecendo Siderópolis. 4 ed. Siderópolis: Prefeitura Municipal de Siderópolis, 2002. $71 \mathrm{p}$.

SIDERÓPOLIS. Lei no 1693, de 20 de julho de 2007. Siderópolis, 2007. 
SIDERÓPOLIS. Lei no 850/91, de 02 de agosto de 1991. Siderópolis, 1991.

WARMELLING, Douglas Gleen. Entrevista concedida a Elaine Rodrigues. Siderópolis 03 de Fev. de 2016. Entrevista. 